\title{
Interleukin-34 sustains pro-tumorigenic signals in colon cancer tissue
}

\author{
Eleonora Franzè ${ }^{1}$, Vicenzo Dinallo ${ }^{1}$, Angela Rizzo $^{1}$, Martina Di Giovangiulio ${ }^{1}$, \\ Gerolamo Bevivino ${ }^{1}$, Carmine Stolfi ${ }^{1}$, Flavio Caprioli ${ }^{2}$, Alfredo Colantoni ${ }^{1}$, Angela \\ Ortenzi ${ }^{1}$, Antonio Di Grazia ${ }^{1}$, Giuseppe Sica ${ }^{3}$, Pier Paolo Sileri ${ }^{3}$, Piero Rossi ${ }^{3}$ and \\ Giovanni Monteleone ${ }^{1}$ \\ ${ }^{1}$ Department of Systems Medicine, University of Rome "TOR VERGATA", Rome, Italy \\ ${ }^{2}$ Department of Pathophysiology and Transplantation, University of Milan, Milan, Italy \\ ${ }^{3}$ Department of Surgery, University "TOR VERGATA" of Rome, Rome, Italy \\ Correspondence to: Giovanni Monteleone, email: Gi.Monteleone@Med.uniroma2.it \\ Keywords: IL-34; colorectal cancer; tumorigenesis; M-CSF-1; ERK I/2 \\ Received: July 29, $2017 \quad$ Accepted: November 17, $2017 \quad$ Published: December 15, 2017 \\ Copyright: Franzè et al. This is an open-access article distributed under the terms of the Creative Commons Attribution License \\ 3.0 (CC BY 3.0), which permits unrestricted use, distribution, and reproduction in any medium, provided the original author and \\ source are credited.
}

\section{ABSTRACT}

Interleukin-34 (IL-34), a cytokine produced by a wide range of cells, binds to the macrophage colony-stimulating factor receptor (M-CSFR-1) and receptor-type protein-tyrosine phosphatase zeta (PTP-z) and controls myeloid cell differentiation, proliferation and survival. various types of cancers over-express IL-34 but the role of the cytokine in colorectal cancer (CRC) remains unknown. We here investigated the expression and functional role of IL-34 in CRC. A more pronounced expression of IL-34 was seen in CRC samples as compared to matched normal/benign colonic samples and this occurred at both RNA and protein level. Immunohistochemical analysis of CRC tissue samples showed that both cancer cells and lamina propria mononuclear cells over-expressed IL-34. Additionally, CRC cells expressed both M-CSFR-1 and PTP-z, thus suggesting that CRC cells can be responsive to IL-34. Indeed, stimulation of DLD-1 cancer cells with IL-34, but not with MSCF1, enhanced the cell proliferation and cell invasion without affecting cell survival. Analysis of intracellular signals underlying the mitogenic effect of IL-34 revealed that the cytokine enhanced activation of ERK1/2 and pharmacologic inhibition of ERK1/2 abrogated IL-34-driven cell proliferation. Consistently, IL-34 knockdown in HT-29 cells with a specific IL-34 antisense oligonucleotide reduced ERK1/ 2 activation, cell proliferation and enhanced the susceptibility of cells to Oxaliplatin-induced death. This is the first study showing up-regulation of IL-34 in CRC and suggesting a role for this cytokine in colon tumorigenesis.

\section{INTRODUCTION}

Colorectal carcinoma (CRC) is one of the most common forms of malignancy and the second leading cause of cancer-related death in the Western world [1]. Chronic inflammation is an independent risk factor for the development of CRC [2]. Approximately 2\% of CRC cases arise in patients with long-standing and extensive ulcerative colitis, one of the 2 major forms of inflammatory bowel diseases (IBD) in humans, while the majority of CRCs develops in individuals who are not affected by IBD [3]. However, even in these latter patients, the neoplastic tissue is massively infiltrated with immune cells, including T cells, natural killer (NK) cells and macrophages cells, which can either foster or inhibit the survival and growth of CRC cells, mostly through the 
production of cytokines [4]. Additional protumorigenic signals originate from other cells present in the tumor tissue, such as tumor-associated macrophages and cancer-associated fibroblasts, whose functions are under the control of factors secreted by neoplastic cells, immune cells and stromal cells [5].

Interleukin-34 (IL-34) is a cytokine produced by a wide range of cells, including macrophages, endothelial cells, fibroblasts, neurons and epithelial cells and is constitutively expressed in adult human tissues, such as heart, brain, liver, spleen, thymus, testis, ovary, prostate, small intestine and colon [6-9]. IL-34 shares no apparent sequence homology with macrophage co type lonystimulating factor (M-CSF-1; also known as CSF-1) but its biological activity is mediated by interaction with the homodimeric M-CSF receptor 1 (M-CSFR-1; also known as CFS-1R or FMS) [10, 11]. M-CSFR-1 is mainly expressed on cell surface of macrophages and to a lesser extent by non-immune cells, such as trophoblasts, osteoclasts, smooth muscle cells and neurons [12-14]. IL-34/M-CSFR-1 signaling regulates myeloid cell differentiation, proliferation and survival and enhances secretion of pro-inflammatory cytokines and chemokines in various systems [12, 15-18]. A second uncovered receptor of IL-34, PTP- $\zeta$, has been recently described [19].

Elevated levels of IL-34 are detectable in patients with various types of cancers, such as blood, brain, breast, eye, head and neck, lung, ovarian and skin cancer, and it has been demonstrated that IL-34 expression is associated with the progression of such tumours [6, 20-24]. There is also evidence that IL-34 plays a role in tumorigenesis given its ability to stimulate endothelial cell proliferation, vascular cord formation and recruitment of macrophages into the tumor tissue $[20,25]$. However, the role of IL-34 in sporadic CRC is unknown. We here investigated the expression and functional role of IL-34 in CRC.

\section{RESULTS}

\section{Sporadic colorectal cancer over-expresses IL-34}

To examine if IL-34 expression is differently regulated during $\mathrm{CRC}$, total RNA was extracted from paired colonic samples of non-tumoral and tumoral areas of patients with sporadic CRC and analyzed by real-time PCR. Tumoral samples expressed higher IL-34 RNA levels than non-tumoral samples of the same CRC patients (Figure 1A). Western blotting of total proteins extracted from freshly obtained samples and densitometry analysis of blots confirmed up-regulation of IL-34 in the tumoral samples (Figure 1B). Consistently, IL-34 protein level measured by ELISA was significantly increased in extracts of tumoral area than in those of non-tumoral area of CRC patients (Figure 1C). Immunohistochemistry analysis of CRC sections showed that IL-34 was mostly produced by cancer cells and to lesser extent by lamina propria mononuclear cells (LPMC) while staining of normal colonic sections revealed that IL-34 was weakly expressed by LPMC and virtually absent in epithelial cells (Figure 1D).

To examine whether IL-34 production is regulated by inflammatory cytokines that are over-produced in CRC tissue [26-29], DLD-1 cells were stimulated with TNF- $\alpha$, IL-6, IL-17A and IFN- $\gamma$ and IL-34 secretion was evaluated by ELISA. In each of 3 independent experiments, all these cytokines enhanced IL-34 secretion (Table 1).

\section{Enhanced expression of M-CSFR-1 in CRC}

To begin to examine whether IL-34 controls CRC cell behavior, we analyzed expression of IL-34 receptors in paired colonic samples taken from tumoral and nontumoral areas of CRC patients. M-CSFR-1 expression quantitated by densitometry and normalized by $\beta$-actin expression was significantly increased in proteins extracted from tumoral areas as compared to samples of non-tumoral areas (Figure 2A). Immunohistochemical analysis confirmed such data and showed that CRC cells were strongly positive for this receptor (Figure 2B). Western blotting showed that PTP-z was detectable in all the samples with no apparent difference between tumoral and non-tumoral areas (Figure 2A). Immunohistochemical analysis showed that such a receptor was expressed by both epithelial cells and LPMC in non-tumoral and tumoral areas (Figure 2B). Consistently, both receptors were seen in HCT-116 and DLD-1, two CRC cell lines (Supplementary Figure 1). Altogether, these data indicate that $\mathrm{CRC}$ cells have the potential to functionally respond to locally-produced IL-34.

\section{IL-34 enhances CRC cell proliferation and cell invasion}

Next, we investigated whether IL-34 controls CRC cell growth, survival and invasion. IL-34 enhanced DLD-1 and HT-29 cell growth, an effect that was mainly evident at a final concentration of $50 \mathrm{ng} / \mathrm{ml}$ (Figure 3A, Supplementary Figure 2A). In contrast, no significant change in the percentages of Annexin V (AV)/propidium iodide (PI)-positive cells was seen following stimulation of CRC cells with IL-34 (Figure 3B, Supplementary Figure 2B). Similarly, IL-34 did not significantly affect the fractions of AV/PI-positive cells induced by FAS Ligand or TNF- $\alpha$ (Figure 3C-3D). The proliferative effect of IL-34 appeared to be specific on CRC cells, as IL-6 but not IL-34 increased the growth of HCEC-1C, a normal colon epithelial cell line (Supplementary Figure 2C). Moreover, by using a matrigel invasion assay, we showed that IL-34 enhanced DLD-1 cell invasion (Figure 4). No significant change in cell proliferation and viability was seen following stimulation of DLD-1 cells with M-CSF-1 (Figure 5A-5B). 


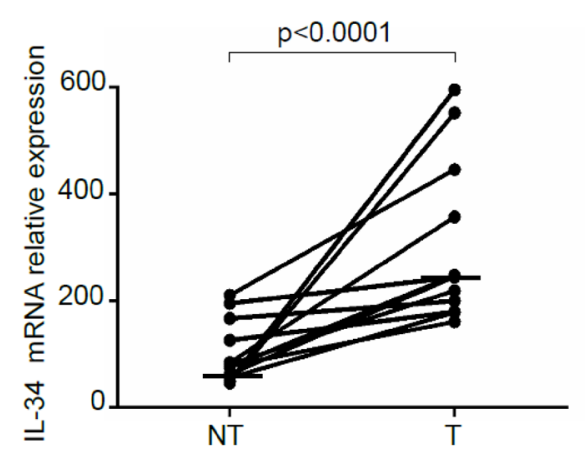

B
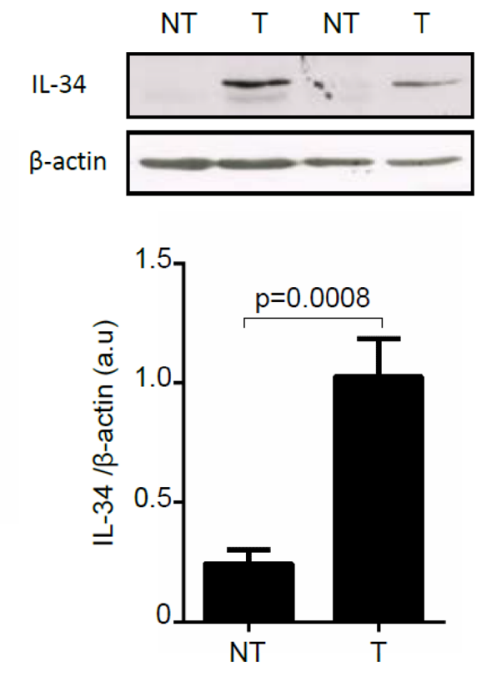

C

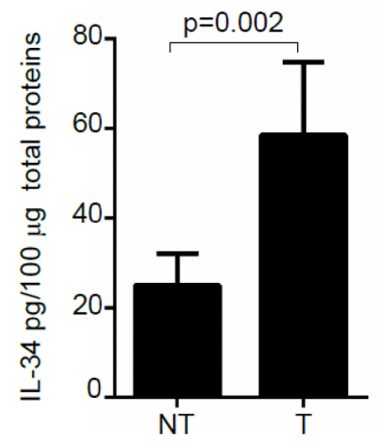

D

NT
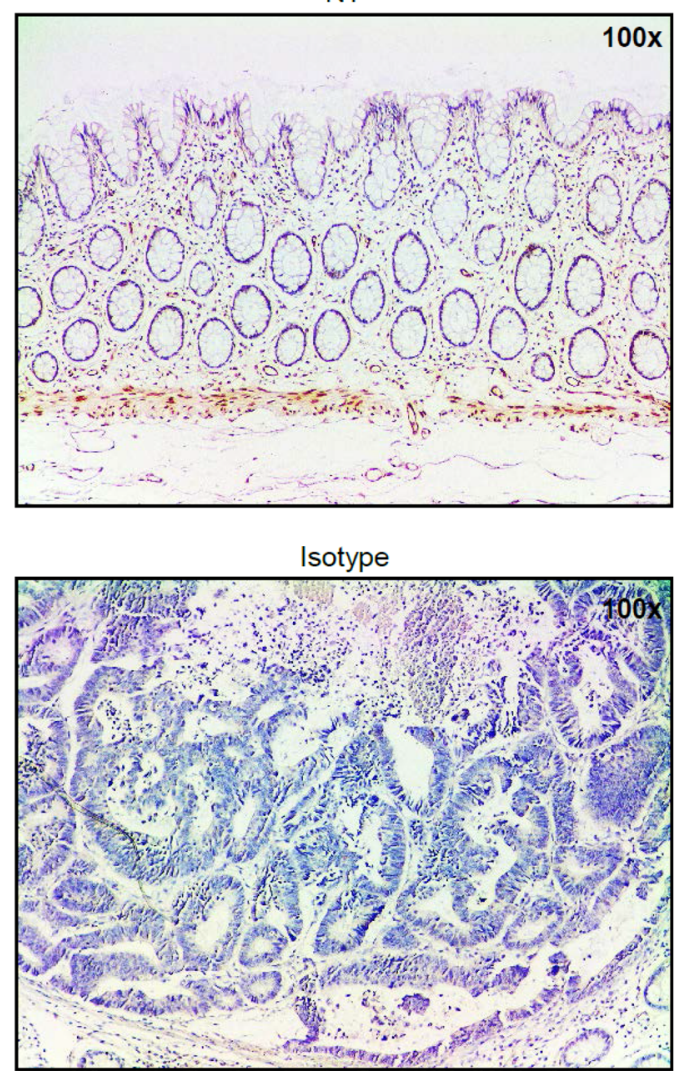

T
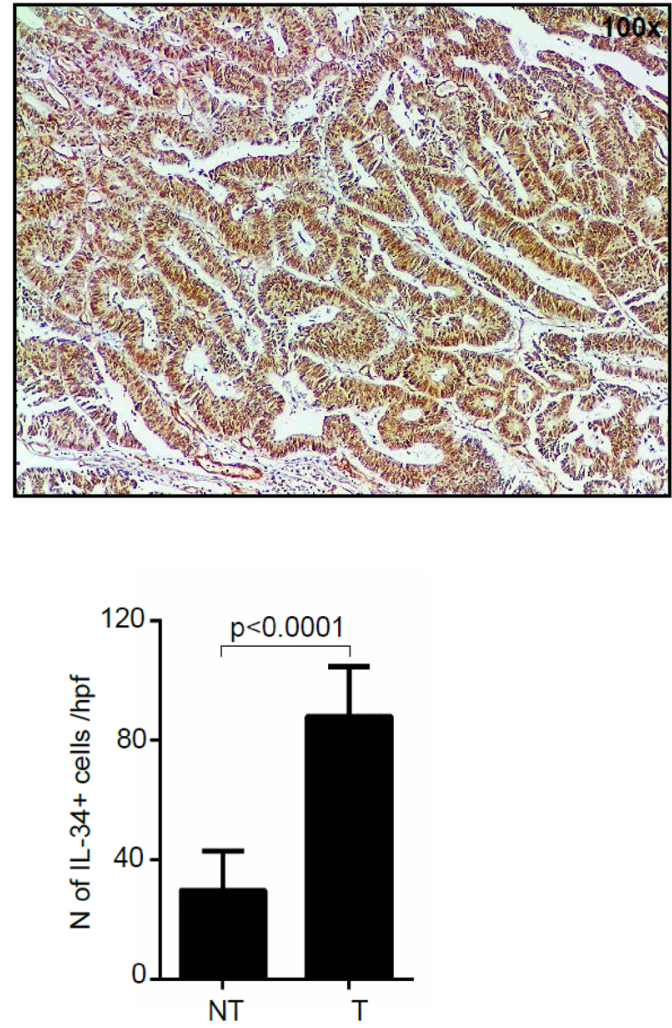

Figure 1: Interleukin-34 (IL-34) RNA transcripts and protein are increased in sporadic colorectal cancer (CRC). (A) Paired colonic explants taken from non-tumoral (NT) and tumoral (T) areas of 12 patients with sporadic CRC were analyzed for IL34 RNA expression by real-time PCR and levels were normalized to $\beta$-actin. Each point represents the value of IL-34 mRNA in a single patient and horizontal bars indicate the median value. (B) Representative Western blots showing IL-34 and $\beta$-actin in total proteins extracted from paired non-tumoral (NT) and tumoral (T) areas of two patients with sporadic CRC. Bottom panels show the quantitative analysis of IL-34/ $\beta$-actin ratio in samples taken from paired non-tumoral (NT) and tumoral (T) areas of 5 CRC patients as measured by densitometry scanning of Western blots. Values are expressed in arbitrary units (a.u.) and indicate mean \pm SEM of all samples. (C) Quantitative analysis of IL-34 protein expression in paired colonic explants taken from the non-tumoral (NT) and tumoral (T) areas of 8 patients with sporadic CRC were measured by ELISA. Data were expressed as mean \pm SEM of all samples. (D) Representative photomicrographs $(100 \times$ original magnification) of IL-34-stained frozen sections of surgical specimens taken from non-tumoral (NT) and tumoral (T) areas of one patient with sporadic CRC. Staining with isotype control antibody is also shown. Right panel shows the number of IL-34-positive cells for high power field (hpf) of 8 separate experiments in which sections of 8 CRC patients were analyzed. Data are expressed as mean $\pm \mathrm{SEM}$. 
Table 1: IL-34 is induced by TNF- $\alpha$, IL-6, IL-17A and IFN- $\gamma$ in DLD-1 cancer cells

\begin{tabular}{|c|c|c|c|c|c|}
\hline Experiment & UNST & TNF- $\alpha(20 \mathrm{ng} / \mathrm{ml})$ & IL-6 (50 ng/ml) & IL-17A (20 ng/ml) & IFN- $\gamma(100 \mathrm{ng} / \mathrm{ml})$ \\
\hline $1^{\circ}$ & 44,6 & 114,8 & 81,9 & 82,8 & 119 \\
\hline $2^{\circ}$ & 27,1 & 53,9 & 54,9 & 57 & 143 \\
\hline $3^{\circ}$ & 28,1 & 51,9 & 40,5 & 54,9 & 155 \\
\hline
\end{tabular}

DLD-1 cells were stimulated with TNF- $\alpha$ (20 ng/ml), IL-6 (50 ng/ml), IL-17 A (20 ng/ml) and IFN- $\gamma$ (100 ng/ml). After 48 hours, cell-free culture supernatants were collected and analyzed by ELISA. Data are expressed as pg/ml and indicate the values of IL-34 measured in supernatants of 3 independent experiments

\section{IL-34 stimulates CRC cell proliferation via ERK1/2-dependent pathway}

In the subsequent studies, we explored the basic mechanism by which IL-34 regulates positively CRC cell growth. Initially, we examined whether
IL-34 activates signalling pathways that control neoplastic cell proliferation. To this end, DLD-1 cells were either left unstimulated or stimulated with IL-34 or TNF- $\alpha$, IL-6 or IL-22, which were used as positive inducers of MAP Kinases, NF$\mathrm{K} \beta$ and STAT3 signalling respectively [30-34].

A
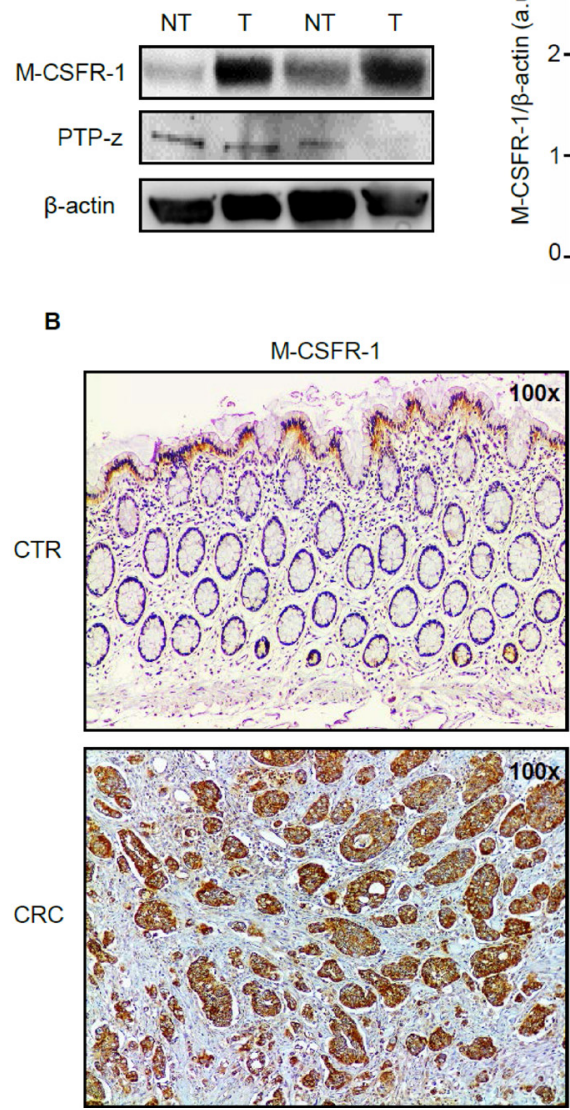
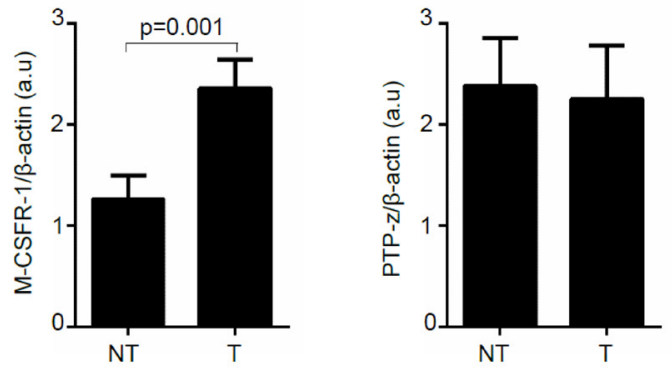
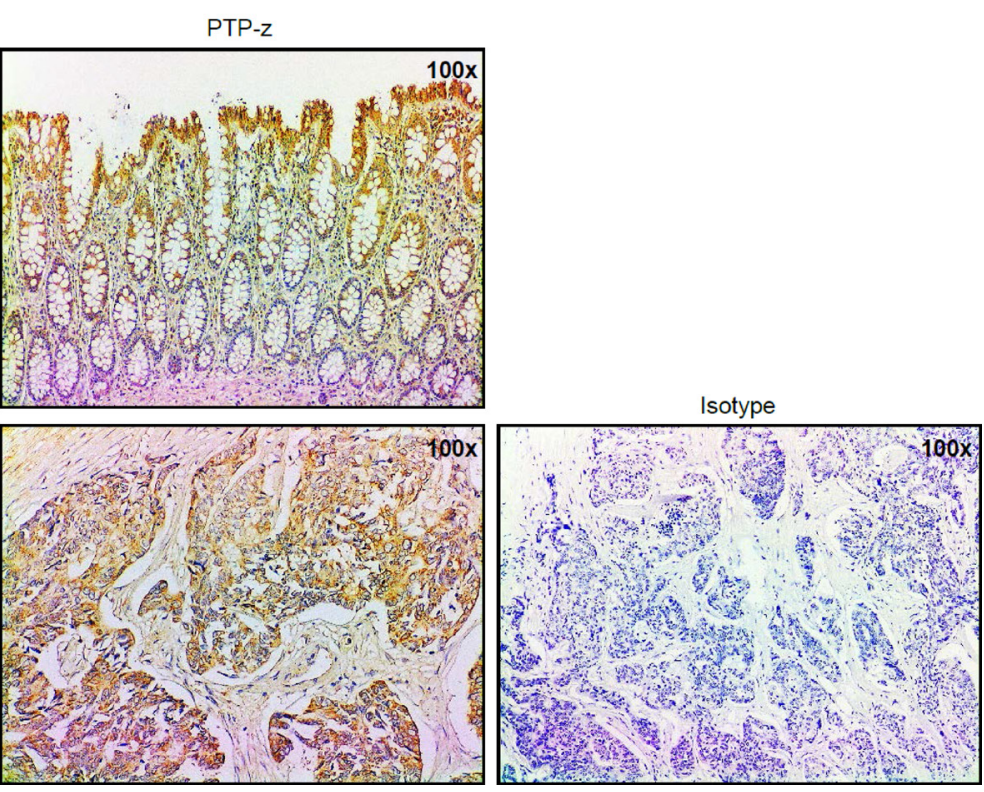

Figure 2: Macrophage colony-stimulating factor -1 receptor (M-CSFR-1) but not Receptor-type tyrosine-protein phosphatase zeta (PTP-z) is increased in sporadic colorectal cancer (CRC). (A) Representative Western blots showing M-CSFR-1, PTP-z and $\beta$-actin in total proteins extracted from paired non-tumoral (NT) and tumoral (T) areas of 2 patients with sporadic CRC. Right panels show the quantitative analysis of M-CSFR- $1 / \beta$-actin and PTP-z/ $\beta$-actin ratio respectively in paired non-tumoral (NT) and tumoral (T) areas taken from 5 CRC patients as measured by densitometry scanning of Western blots. Values are expressed in arbitrary units (a.u.) and indicate mean \pm SEM of all samples. (B) Representative photomicrographs (100x original magnification) of M-CSFR-1and PTP-z stained paraffin-embedded sections of surgical colonic samples taken from one control (CTR) and one patient with sporadic CRC. The figure is representative of 3 separate experiments in which sections taken from 4 CTR and 3 patients with CRC were analyzed for M-CSFR-1 and PTP-z. Staining with isotype control antibody is also shown. 
IL-34 enhanced phosphorylation of both ERK1/2 and p38 MAP Kinases without affecting phosphorylation of STAT3 and NF-K $\beta$ /p65 (Figure 6A). To test whether ERK1/2 and p38 activation mediates IL-34-driven DLD-1 cell growth, cells were pre-incubated with specific inhibitors of these two MAP Kinases prior to being stimulated with IL-34. Treatment of DLD-1 cells with PD98059, an inhibitor of ERK1/2, but not with SB202190, a p38 inhibitor, abrogated IL-34-induced DLD-1 cell proliferation (Figure 6B).

A
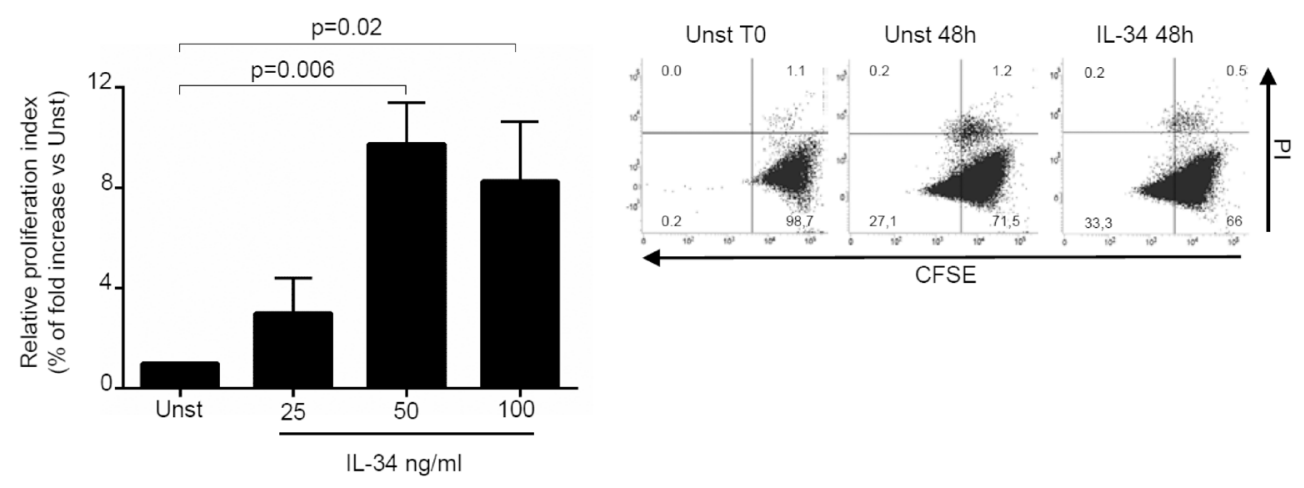

B

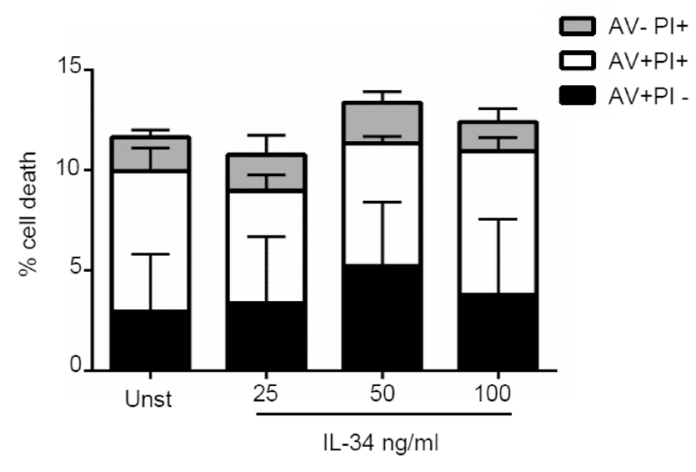

C

D
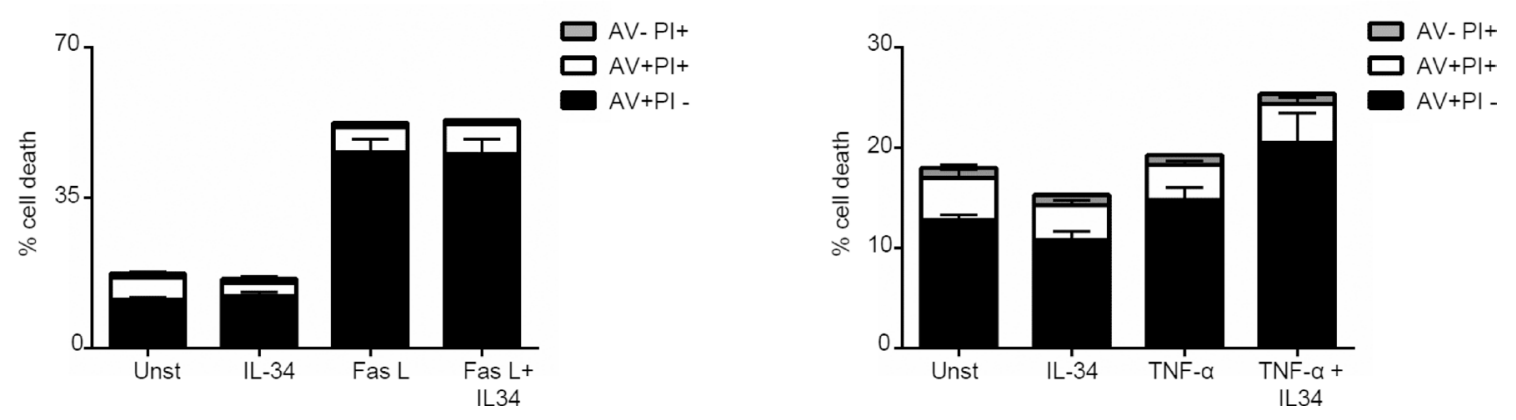

Figure 3: Interleukin-34 (IL-34) induces CRC cell proliferation but does not affect cell death. (A) Serum-starved DLD-1 cells were either left unstimulated (Unst) or stimulated with increasing doses of recombinant human IL-34 (25-100 ng/ml) for 48 hours. Cell proliferation was evaluated by flow cytometry and proliferation index was calculated with Modfit LT. Data indicate mean \pm SEM of 4 independent experiments. Right insets: representative dot-plots showing the percentages of CFSE- and/or PI-positive cells before and after IL-34 stimulation. (B) Serum-starved DLD-1 cells were either left unstimulated (Unst) or stimulated with increasing doses of recombinant human IL-34 (25-100 ng/ml) for 48 hours. Data indicate the percentage of cell death as assessed by flow cytometry analysis of AV and/or PIpositive cells and are expressed as mean \pm SEM of 4 experiments. (C) Serum-starved DLD-1 cells line were either left unstimulated (Unst) or stimulated with recombinant human IL-34 (50 ng/ml) and/or Fas Ligand (Fas L) (200 ng/ml) for 48 hours. The percentage of cell death was assessed by flow cytometry analysis of AV and/or PI-positive cells. Data indicate mean \pm SEM of 4 independent experiments. (D) Serumstarved DLD-1 cells were either left unstimulated (Unst) or stimulated with recombinant human IL-34 (50 ng/ml) and/or TNF- $\alpha$ (100 ng/ml) for 48 hours. The percentage of cell death was assessed by flow cytometry analysis of AV and/or PI-positive cells. Data indicate mean \pm SEM of 4 independent experiments. 


\section{IL-34 knockdown with a specific antisense oligonucleotide reduces CRC cell growth}

To confirm that CRC cell-derived IL-34 regulates positively CRC cell proliferation, we inhibited IL34 in HT-29 cells with a specific IL-34 antisense oligonucleotide. For these experiments, we selected HT29 cells as this cell line expresses elevated levels of IL-34 (Figure 7A). Treatment of HT-29 cells with the specific
IL-34 antisense oligonucleotide decreased IL-34 protein expression (Figure 7B) and phosphorylation of ERK1/2 and ELK1, a down-stream target of ERK1/2 (Figure 7C). IL-34 knockdown was associated with a significant reduction of cell growth (Figure 7D) but no change in cell viability (Figure 7E). Finally, treatment of HT-29 cells with IL-34 antisense oligonucleotide enhanced the susceptibility of cells to oxaliplatin (OXL)-induced death while cells were resistant to 5-Fluorouracile (5-FU)

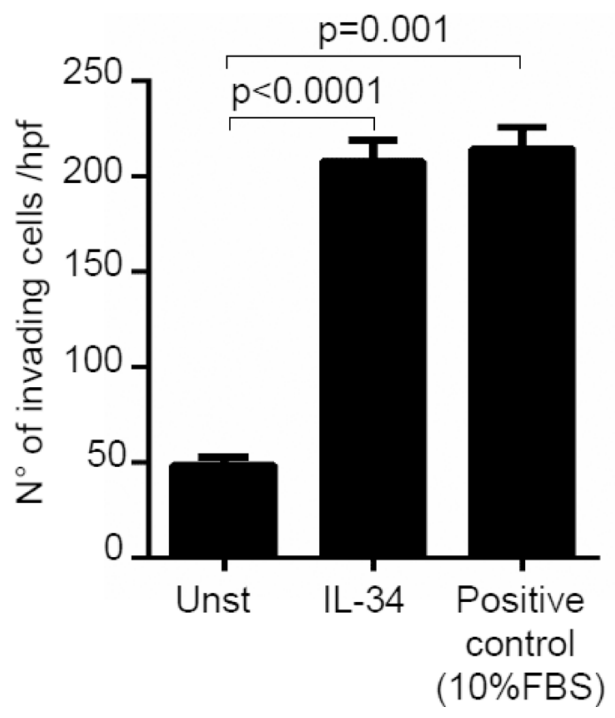

Figure 4: Interleukin-34 (IL-34) induces CRC cell invasion. DLD-1 cells $\left(3 \times 10^{4}\right)$ were seeded in Transwell inserts precoated with Matrigel, and either left unstimulated (Unst) or stimulated with IL-34 $(50 \mathrm{ng} / \mathrm{ml}$ ) or $10 \%$ fetal bovine serum (FBS) (used as positive control of invasion) for 48 hours. Data are expressed as mean \pm SEM of three independent experiments.

A

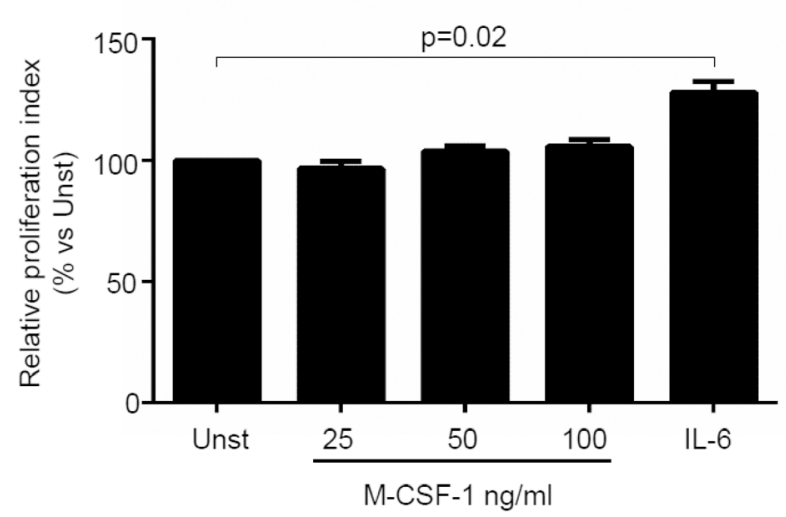

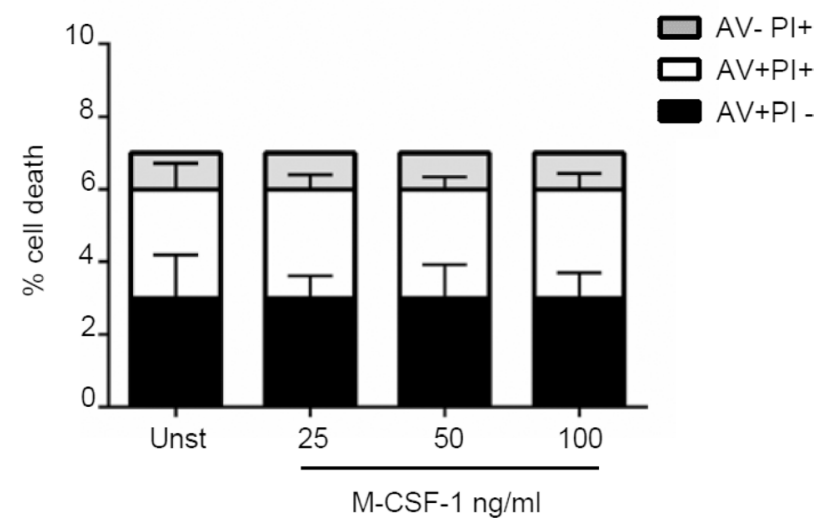

Figure 5: Macrophage colony-stimulating factor -1 (M-CSF-1) does not affect CRC cell growth and death. (A) Serumstarved DLD-1 cells were either left unstimulated (Unst) or stimulated with increasing doses of recombinant human M-CSF-1 (25-100 ng/ $\mathrm{ml})$ or IL-6 (50 ng/ml, used as a positive control) for 48 hours. Cell proliferation was evaluated with CFSE staining by flow cytometry. Data indicate mean \pm SEM of four independent experiments. (B) Serum-starved DLD-1 cells were either left unstimulated (Unst) or stimulated with increasing doses of recombinant human M-CSF-1 $(25-100 \mathrm{ng} / \mathrm{ml})$ for 48 hours. The percentage of cell death was assessed by flow cytometry analysis and expressed as percentage of AV and/or PI-positive cells. Data are expressed as mean $\pm \mathrm{SEM}$ of 6 independent experiments. 
and Irinotecan (CPT-11), regardless of whether IL-34 expression was silenced (Figure 7F).

\section{DISCUSSION}

Although the exact sequence of events that sustain CRC growth remains poorly characterized, there is evidence that cytokines produced by immune cells and stromal cells exert proliferative effects on CRC cells [4, $35]$. On the other hand, CRC cells can produce additional factors that acting in a paracrine/autocrine manner expand further cell growth [36]. Identifying such molecules and the molecular mechanisms underlying CRC cell growth could help design novel therapeutic strategies for patients with advanced CRC.

The present study was undertaken to examine the expression and functional role of IL-34 in human CRC. By using various assays, we initially showed that IL34 is constitutively expressed in the normal colon and its expression is increased in tumoral samples of CRC patients. Analysis of cell sources of IL-34 showed that both cancer cells and mononuclear cells infiltrating the tumoral tissue produce elevated levels of the cytokine. Normal colonic mucosa, adjacent to the tumoral area,

A

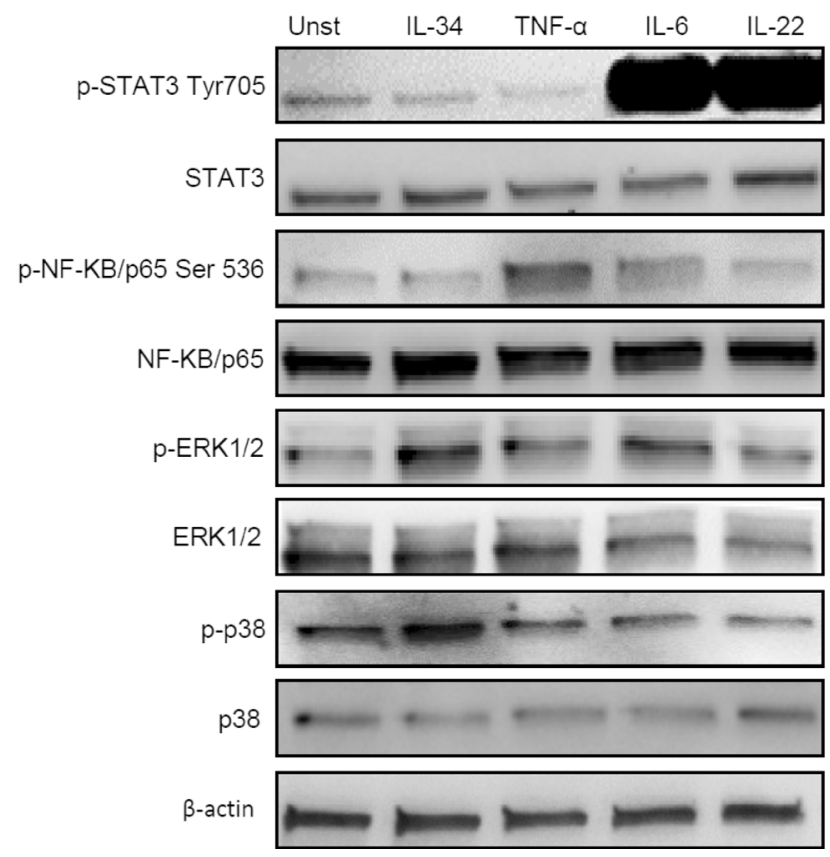

expressed low levels of IL-34, thus suggesting that stimuli generated within the tumoral microenvironment can elicit IL-34 production. In this context, data of the present study indicate that cytokines over-produced by immune cells infiltrating the CRC tissue, such as TNF- $\alpha$, IL-6, IL$17 \mathrm{~A}$ and IFN- $\gamma$ [26-29], enhance IL-34 production. The fact that IL-34 expression was enhanced by IFN- $\gamma$ could appear inconsistent with the notion that IFN- $\gamma$ stimulates anti-tumor adaptive immune response. However, there is evidence that, in specific conditions IFN- $\gamma$ is protumorigenic [29, 37].

We show also CRC cells express both M-CSFR-1 and PTP-z, the two known IL-34 receptors, and, therefore, are potentially capable of responding to the cytokine. Indeed, stimulation of CRC cells with IL-34 resulted in enhanced cell growth and cell invasion, while the cytokine did not alter CRC cell viability. Treatment of CRC cells with M-CSF-1, another ligand of M-CSFR-1, associated with no change in cell growth and survival. These findings are in line with results of previous studies showing that IL-34 and M-CSF-1 exert non-redundant functions though they share a common receptor [10]. The divergent functions of these two cytokines could rely on their ability to differently bind and signal through the receptor

B

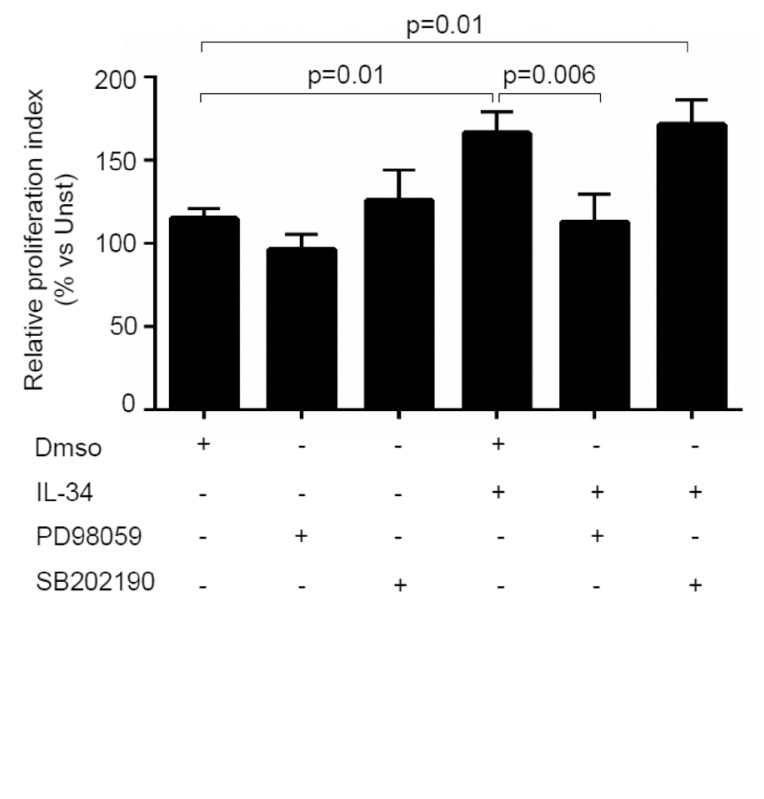

Figure 6: Interleukin-34 (IL-34) induces CRC cell proliferation through an ERK1/2-dependent mechanism. (A) Serumstarved DLD-1 cells were either left unstimulated (Unst) or stimulated with IL-34 (50 ng/ml), TNF- $\alpha$ (25 ng/ml), IL-6 (25 ng/ml), IL-22 $(25 \mathrm{ng} / \mathrm{ml})$ for 15 minutes. Phosphorylated and total forms of the STAT3, NF-KB/p65, ERK1/2, p38, and $\beta$-actin were evaluated by Western blotting. One of 4 independent experiments is shown. (B) Serum-starved DLD-1 cells were pre-incubated with either specific inhibitors of ERK1/2 and p38 (PD98059 and SB202190 respectively) or with Dimethyl sulfoxide (DMSO, vehicle) for 1 hour and then stimulated with IL-34 $(50 \mathrm{ng} / \mathrm{mL})$ for further 48 hours. Cell proliferation was evaluated by flow cytometry. Data indicate mean \pm SEM of 4 independent experiments. 
A

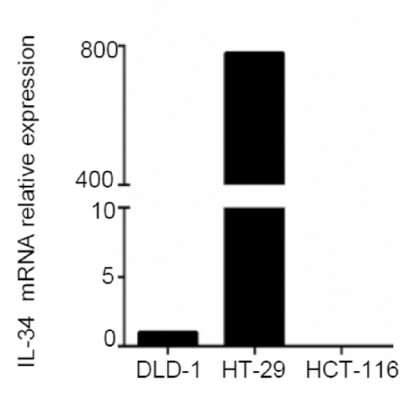

B

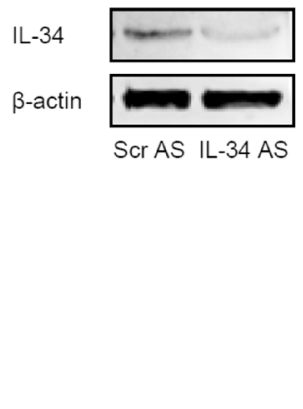

C

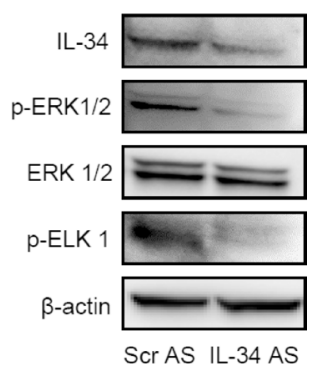

D

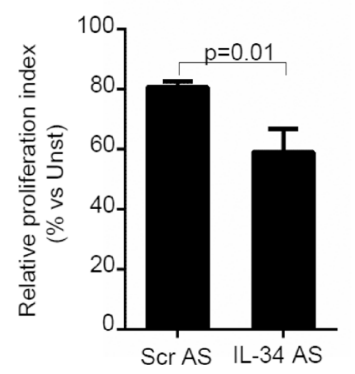

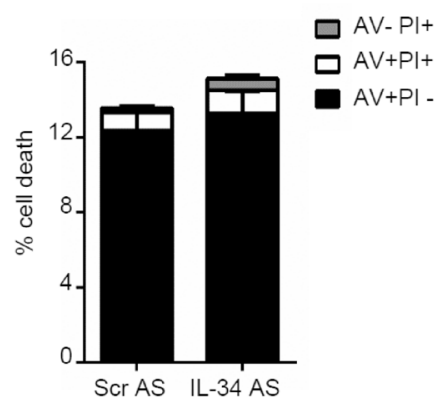

$\mathbf{F}$

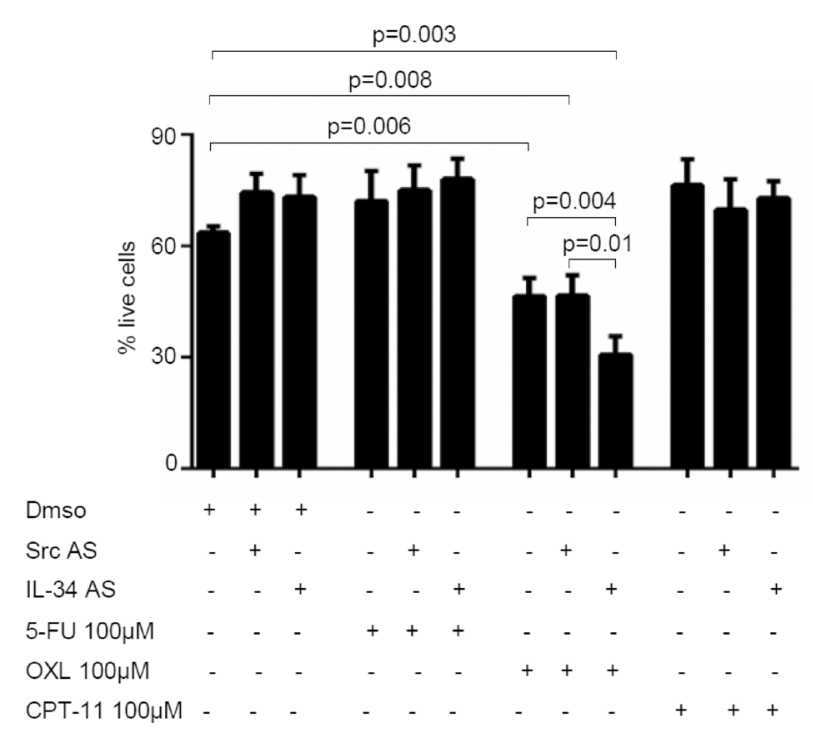

Figure 7: Knockdown of IL-34 with a specific antisense oligonucleotide decreases HT-29 cell proliferation and increases oxaliplatin-induced cell death. (A) IL-34 was evaluated in the human CRC cell lines DLD-1, HT-29 and HCT-116 by real-time PCR and levels were normalized to $\beta$-actin. (B) HT-29 cells were transfected with scrambled negative control oligonucleotide (SCR AS) or IL-34 antisense oligonucleotide (IL-34 AS) (both used at $2 \mu \mathrm{g} / \mathrm{ml}$ ) for 48 hours. IL-34 and $\beta$-actin were analyzed by Western blotting. One of 4 independent experiments is shown. (C) HT-29 cells were transfected with either SCR AS or IL-34 AS (both used at $2 \mu \mathrm{g} / \mathrm{ml}$ ) for 72 hours. Phosphorylated and total forms of ERK1/2, ELK 1, IL-34 and $\beta$-actin were evaluated by Western blotting. One of 4 independent experiments is shown. (D) HT-29 cells were transfected with either SCR AS or IL-34 AS (both used at $2 \mu \mathrm{g} / \mathrm{ml}$ ) for 72 hours. Cell proliferation was evaluated by flow cytometry following staining with CFSE. Data indicate mean \pm SEM of 4 independent experiments. (E) HT-29 cells were transfected with either SCR AS or IL-34 AS (both used at $2 \mu \mathrm{g} / \mathrm{ml}$ ) for 72 hours. The percentage of cell death was assessed by flow cytometry. Data are indicated as percentage of AV and/or PI-positive cells and expressed as mean \pm SEM of 4 indipendent experiments. (F) HT-29 cells were transfected with either SCR AS or IL-34 AS (both used at $2 \mu \mathrm{g} / \mathrm{ml}$ ) for $24 \mathrm{hours}$ and then stimulated with 5-Fluorouracile (5-FU), Oxaliplatin (OXL) and Irinotecan (CPT-11) (all used $100 \mu \mathrm{M}$ ) or DMSO (vehicle) for further 24 hours. Data are expressed as mean \pm SEM of 4 independent experiments. 
as previous studies showed that IL-34 is more powerful than M-CSF-1 in triggering M-CSFR-1 activation [38]. The fact that CRC cells express both IL-34 and IL34 receptors raises the possibility that IL-34 acts in an autocrine and/or paracrine manner to regulate CRC cell growth. This hypothesis is supported by the demonstration that knockdown of IL-34 with a specific antisense oligonucleotide in HT-29 cells reduced cell growth without affecting cell apoptosis/necrosis. Moreover, IL34 knockdown enhanced the susceptibility of CRC cells to OXL-induced death. These results are consistent with studies in lung cancer showing that IL-34, produced during chemotherapy, enhances cancer cell survival [22].

Evaluation of the intracellular pathways sustaining CRC cell growth revealed that IL-34 activates ERK1/2 and p38 MAP kinases. However, pharmacological inhibition of ERK1/2 but not of p38 abrogated the ability of IL-34 to enhance CRC cell growth. These findings are in line with the demonstration that M-CSFR-1 has a tyrosine kinase activity and interaction with IL-34 induces the phosphorylation of a tyrosine residue of the receptor cytoplasmic domain and its homodimerisation, with the downstream effect of initiating a cascade of phosphorylation of other proteins, including ERK1/2 [10-12].

Recent studies showed a positive correlation between IL-34 expression and tumor development. For example, IL-34 promotes osteoclastogenesis and appears to be involved in giant cell tumors of bone [6]. Initial evidence suggests the involvement of IL-34 in mammary cancer in which IL-34 levels have been associated with shorter survival and time to recurrence following cytotoxic therapies [24]. In such a neoplasia, as well as in other tumors (i.e. teratoma, hepatocellular carcinoma), the protumoral effect of IL-34 would be linked to the ability of the cytokine to promote the survival and the differentiation of type 2 macrophages [23, 25, 39, 40]. Data of the present study expand on these observations and indicate that IL-34 can directly target cancer cells and stimulate intracellular pathways that positively regulate colon carcinogenesis. This does not however exclude the possibility that IL-34 can control the function of additional cell types, which in turn sustain CRC cell proliferation. For instance, IL34 stimulates intestinal immune cells to make TNF- $\alpha$ and IL-6, two cytokines exerting proliferative effects on CRC cells, and has been involved in the suppressive function of regulatory $\mathrm{T}$ cells, a subset of $\mathrm{T}$ cells whose activity associates with the progression of cancer cells [18, 26, 4143]. Moreover, IL-34 facilitates polarization of memory $\mathrm{T}$ cells into Th17 cells, which enhance cancer cell growth in many organs [44].

In conclusion, this is the first study showing upregulation of IL-34 in CRC and suggesting a role for this cytokine in the growth of CRC cells.

\section{METHODS}

\section{Patients and samples}

Paired tissue samples were taken from the tumoral area and the macroscopically and microscopically unaffected, adjacent colonic mucosa of 26 patients who underwent colon resection for sporadic CRC at the Tor Vergata University Hospital (Rome, Italy) or Fondazione IRCCS Cà Granda, Ospedale Maggiore Policlinico (Milan, Italy). All patients received neither radiotherapy nor chemotherapy prior to undergoing surgery.

Each patient who took part in the study gave written informed consent and the study protocol was approved by the local Ethics Committee (Tor Vergata University Hospital, Rome. Protocol number:171/16).

\section{Intestinal epithelial cell lines}

The human colon cancer cell lines DLD-1 (phenotype: k-ras mutation G13D, p53 wild type), HT29 (phenotype: k-ras wild type, mutated p53) and HCT116 (phenotype: : k-ras mutation G13D, p53 wild type) were cultured in $25 \mathrm{~cm}^{2}$ plastic flasks and maintained at $37^{\circ} \mathrm{C}$ in a humidified atmosphere of $5 \% \mathrm{CO}_{2}$ in RPMI 1640 or McCoy's 5A (all from Lonza, Verviers, Belgium) supplemented with $10 \%$ fetal bovine serum (FBS), penicillin (P) (100 U/ml), streptomycin (S) $(100 \mu \mathrm{g} / \mathrm{ml})$ (all from Lonza). Human colon epithelial cells (HCEC1CT) were cultured in $25 \mathrm{~cm}^{2}$ plastic flasks and maintained at $37^{\circ} \mathrm{C}$ in a humidified atmosphere of $5 \% \mathrm{CO}_{2}$ in medium ColoUpTm (Evercyte GmbH, Muthgasse, Vienna).

To evaluate whether IL-34 or $\mathrm{M}-\mathrm{CSF}-1$ regulate cancer cell growth and viability, $2 \times 10^{5}$ DLD- 1 cells, HT29 cells or HCEC-1CT cells were plated into each well of a 6-wells plate and left to adhere. After 24 hours, cells were starved for 12 hours and then stimulated with recombinant human IL-34 or M-CSF-1 (both used at a final concentration of 25-100 ng/mL, R\&D Systems, Inc. Minneapolis, MN, USA) or IL-6 (50 ng/ml, R\&D Systems) in fresh medium containing $0,05 \%$ bovine serum albumin (BSA) (Sigma) for 48 hours. To evaluate if IL-34 synergizes with apoptotic stimuli, serum-starved DLD-1 cells were either left unstimulated or stimulated with recombinant human IL$34(50 \mathrm{ng} / \mathrm{mL})$ in presence or absence of FasL $(200 \mathrm{ng} / \mathrm{ml}$, Enzo Life, Sciences, NY, USA) or TNF- $\alpha$ (100 ng/ml, R\&D Systems) for 48 hours. At the end of cell culture, cell death was assessed by flow cytometry.

To determine the factors that modulate IL-34 expression, DLD-1 cells were either left unstimulated or stimulated with TNF- $\alpha(20 \mathrm{ng} / \mathrm{ml})$, IL-6 (50 ng/ml), IL-17A (20 ng/ml, R\&D Systems) or IFN- $\gamma(100 \mathrm{ng} / \mathrm{ml}$, Peprotech Ec Ltd,). After 48 hours, cell-free supernatants were analyzed by ELISA. To examine the molecular mechanism that controls the proliferative effect of IL34 on cancer cells, serum-starved DLD-1 cells were 
either left unstimulated or stimulated with recombinant human IL-34 (50 ng/mL), TNF- $\alpha$ (25 ng/mL), IL-6 (25 ng/mL) and IL-22 (25 ng/ml) for 15 minutes, then lysed and total extracts were analyzed for the content of both phosphorylated and total form of MAP kinases (ERK1/2, p38), NF-kB p65 and Stat3 by Western blotting. To evaluate the effect of MAP Kinase on IL-34induced cancer cell proliferation, serum-starved DLD-1 cells were preincubated with PD98059 (50 $\mu \mathrm{M}$, EMD Millipore Corporation, Billerica, MA, USA), a selective inhibitor of ERK1/2, or SB202190, an inhibitor of p38 (10 mol/L, EMD Millipore) or dimethyl sulfoxide (DMSO; vehicle, Sigma-Aldrich, Milan, Italy) for 1 hour and then stimulated or not with IL-34 (50 ng/ml) for 48 hours. The specificity of both ERK1/2 and p38 inhibitors has been previously verified [18]. At the end of cell culture, cell proliferation was assessed by flow cytometry.

In additional experiments, HT-29 cells were either left untreated or transfected with a specific IL-34 antisense oligonucleotide or scrambled antisense oligonucleotide (both used a $2 \mu \mathrm{g} / \mathrm{ml}$, Exiqon, Woburn, MA, USA) for 48-72 hours using Opti-MEM medium and Lipofectamine 3000 reagent (both from Life Technologies, Milan, Italy) according to the manufacturer's instructions. At the end, cell viability and proliferation and ERK1/2 activation were evaluated. The efficiency of the transfection was determined by Western blotting. To evaluate the effect of IL-34 on chemotherapeutic agent-induced CRC cell death, HT-29 cells were transfected with the specific IL-34 antisense oligonucleotide or scrambled antisense oligonucleotide (both used a $2 \mu \mathrm{g} / \mathrm{ml}$, Exiqon,) for 24 hours and then stimulated with 5-FU, OXL or CPT-11 (all used $100 \mu \mathrm{M}$, Sigma) or DMSO (vehicle) for further 24 hours. At the end, cell viability was evaluated by flow cytometry.

\section{Analysis and quantification of cell proliferation and death}

Cell proliferation was assessed by flow cytometry using carboxyfluorescein diacetate succinimidyl ester (CFSE; Molecular Probes, Life Technologies), which covalently binds cell components to yield a fluorescence that is divided equally between daughter cells at each division.

Briefly, starved DLD-1 or HT-29 cells were incubated with CFSE according to the manufacturer's instructions. After $30 \mathrm{~min}$, the medium was removed and fresh medium was added for the indicated time points. At the end, cells were collected, washed twice with PBS, and then incubated with PI (5 mg/ml, Life Technologies) for $15 \mathrm{~min}$ at $4{ }^{\circ} \mathrm{C}$ in the dark. CFSE- and/or PI-positive cells were determined by flow cytometry (FACSVerse BD Biosciences, San Jose, CA, USA) and the data were analyzed using ModFit LT 5.0
(Verity Software House, Inc., Topsham, ME, USA) and expressed as proliferation index relative to unstimulated conditions.

To score cell death, DLD-1 or HT-29 cells, left untreated or stimulated as described above for the indicated time points, were washed in PBS, stained with FITC-AV (1:100 final dilution, Immunotools, Friesoyte, Germany) according to the manufacturer's instructions and incubated with $5 \mathrm{mg} / \mathrm{ml}$ PI (Life Technologies) for $20 \mathrm{~min}$ at $4^{\circ} \mathrm{C}$. Then, the fluorescence was measured by flow cytometry using FL-1 and FL-2 channels of FACSVerse (BD Biosciences) flow cytometer. Viable cells were considered as AV-/PI-cells, apoptotic cells as AV+/PI-cells, whereas secondary necrotic cells were characterized by $\mathrm{AV}+/ \mathrm{PI}+$ staining. Data are expressed as percentage of cell death.

\section{Cell invasion assay}

To evaluate if IL-34 promotes CRC cell invasion, transwell inserts (Corning, Inc., Corning, NY, USA) were precoated with Matrigel matrix (BD Biosciences, Franklin Lakes, NJ, USA) mixed 1:1 with RMPI 1640 (Lonza) at $37^{\circ} \mathrm{C}$ for 6 hours. DLD-1 cells were trypsinized and plated into the upper chambers at a concentration of $3 \times 10^{4}$ cells $/ 100 \mu \mathrm{l}$ in serum-free RPMI 1640 with $0,05 \%$ of BSA (Sigma). The lower chambers were filled with $800 \mu \mathrm{L}$ RPMI-1640 medium containing 0,05\% BSA and IL-34 (50 ng/ml) or 10\% FBS (Lonza), used as positive control of matrigel-invasion. Cells were incubated in a humidified incubator at $37^{\circ} \mathrm{C}$ with $5 \% \mathrm{CO} 2$ for $48 \mathrm{~h}$. Afterwards, cells were fixed in $4 \%$ paraformaldehyde (Sigma) for $2 \mathrm{~min}$ at room temperature, permeabilized with $100 \%$ of Methanol (Sigma) for $20 \mathrm{~min}$ at room temperature, and stained with crystal violet (Sigma). The non-invading cells that remained on the upper surface of the membrane were removed by scraping while the invaded cells were counted using an inverted microscope at a magnification $400 \mathrm{X}$ in at least 8 randomly selected fields using IAS 2000 System (Delta Sistemi, Rome, Italy).

\section{Real-time PCR}

A constant amount of RNA $(0,5 \mu \mathrm{g} /$ sample $)$ was retro-transcribed into complementary DNA (cDNA) and then $1 \mu \mathrm{l}$ of cDNA/sample was amplified using the following conditions: denaturation 1 minute at $95^{\circ} \mathrm{C}$; annealing 30 seconds, at $60^{\circ} \mathrm{C}$ for $\beta$-Actin and IL-34 followed by 30 seconds of extension at $72^{\circ} \mathrm{C}$. Primer sequences: IL-34: forward, 5'- ACAGGAG CCGACTTCAGTAC-3' and reverse, 5'- ACCAAGAC CCACAGATACCG-3'; $\beta$-actin: forward, 5'-AAGATGACC CAGATCATGTTTGAGACC-3' and reverse 5'-AGCCAG TCCAGACGCAGGAT-3'. mRNA expression was calculated relative to the housekeeping $\beta$-Actin gene on the base of the $\Delta \Delta \mathrm{Ct}$ algorithm. 


\section{Total protein extraction and Western blotting}

Paired tissue samples of tumoral and nontumoral areas and colon cancer cells were lysed on ice in buffer containing $10 \mathrm{mM}$ HEPES ( $\mathrm{pH}$ 7.9), $10 \mathrm{mM} \mathrm{KCl}, 0.1 \mathrm{mM}$ EDTA, $0.2 \mathrm{mM}$ EGTA and $0.5 \%$ Nonidet P40 supplemented with $1 \mathrm{mM}$ dithiothreitol, $10 \mathrm{mg} / \mathrm{ml}$ aprotinin, $10 \mathrm{mg} / \mathrm{ml}$ leupeptin, $1 \mathrm{mM}$ phenylmethylsulfonyl fluoride, $1 \mathrm{mM} \mathrm{Na} 3 \mathrm{VO} 4$ and $1 \mathrm{mM}$ $\mathrm{NaF}$. Lysates were clarified by centrifugation at $4^{\circ} \mathrm{C}$, $12.000 \times \mathrm{g}$ for 30 minutes, and separated on $10 \%$ sodium dodecyl sulphate-polyacrylamide gel electrophoresis. IL34, M-CSFR-1, PTP-z, phosphorylated (p) ERK1/2, ELK1, p-p38, p-STAT3 and p-NF-kB p65 were detected using the following antibodies: mouse anti human IL-34 (1:1000 Abcam, Cambridge, UK), rabbit anti-human M-CSFR-1 (1:500 Novus Biological, Littleton, CO, USA), rabbit anti-human PTP-z (1:1000 Abcam), mouse anti-human p-ERK 1/2 (1:500 Santa Cruz Biotechnology, Inc., Dallas, TX, USA), mouse anti-human p-ELK 1 (1:500 Santa Cruz Biotechnology, Inc., Dallas, TX, USA), rabbit antihuman p-p38 (1:1000 EMD Millipore Corporation), rabbit anti human p-STAT3 Tyr705 (Cell Signaling, Danvers, MA, USA), rabbit anti human p-NF-кB/p65 Ser536 (Cell Signaling), respectively, followed by horseradish peroxidaseconjugated secondary IgG monoclonal antibodies (all used at 1:20000 final dilution, Dako, Milan, Italy). The reaction was detected with a sensitive enhanced chemiluminescence kit (Pierce, Rockford, IL, USA). After the analysis, blots were stripped and incubated with the following internal loading controls: mouse anti-human $\beta$-actin antibody (final dilution 1:5000 Sigma-Aldrich), rabbit anti-human total ERK1/2 (1:500, Santa Cruz Biotechnology), mouse anti-human total p38, rabbit anti- human NF- $\mathrm{BB} / \mathrm{p} 65$ and mouse antihuman total STAT3 (at 1:500, Santa Cruz Biotechnology) followed by horseradish peroxidase-conjugated secondary IgG monoclonal antibodies (all used at 1:20000 final dilution, Dako).

\section{Immunohistochemistry}

Immunohistochemistry was performed on archival frozen sections of paired tumoral and nontumoral samples of $8 \mathrm{CRC}$ patients. Freshly obtained samples were embedded in a cryostat mounting medium (Neg-50 Frozen Section Medium, Thermo Scientific, Langenselbold, Germany), snap frozen and stored at $-80^{\circ} \mathrm{C}$. Six $\mu \mathrm{m}$-thickened sections were mounted onto superfrost plus glass slides (Thermo Scientific) and fixed in $4 \%$ neutral buffered formalin for 10 minutes at room temperature and then in increasing ethanol solutions. After washing in Tris Buffered Saline, endogenous peroxidase activity was quenched with $3 \% \mathrm{H}_{2} \mathrm{O}_{2}$ diluted in methanol for 10 minutes at room temperature. The slides were incubated with a mouse monoclonal antibody directed against human IL-34 (final dilution 1:50000, Abcam,
Cambridge, UK) at room temperature for 1 hour followed by a biotin-free HRP-polymer detection technology (Ultravision Detection System, Thermo Scientific, Waltham, MA, USA) with 3,3'diaminobenzidine (DAB) as a chromogen (Dako). The sections were counterstained with haematoxylin, dehydrated and mounted. Isotype control IgG-stained sections were prepared under identical immunohistochemical conditions as described above, replacing the primary antibody with a purified mouse normal IgG control antibody (R\&D Systems). The IL-34positive cells were counted in at least 6 fields per section using IAS 2000 System (Delta Sistemi, Rome, Italy) and expressed as number of cells for high power field (hpf). Moreover, immunohistochemistry was performed on formalin-fixed paraffin-embedded sections of non-tumoral and tumoral samples of $6 \mathrm{CRC}$ patients. The sections were deparaffinized and dehydrated through xylene and ethanol and the antigen retrieval was performed in Tris EDTA citrate buffer $(\mathrm{pH} 7.8)$ for 30 minutes in thermostatic bath at $98^{\circ} \mathrm{C}$ (Dako). Immunohistochemical staining was performed using a rabbit monoclonal antibody directed against human M-CSFR-1 (final concentration 1:200, Novus Biological) or rabbit anti-human PTP-z (1:100 Abcam) at room temperature for 1 hour followed by a biotin-free HRP-polymer detection technology with DAB as a chromogen (MACH 4 Universal HRP-Polymer Kit, Biocare Medical). The sections were counterstained with haematoxylin, dehydrated and mounted. Isotype control IgG-stained sections were prepared under identical immunohistochemical conditions as described above, replacing the primary antibody with a purified mouse or rabbit normal IgG control antibody.

\section{Enzyme-linked immunosorbent assay (ELISA)}

Human IL-34 was measured using a sensitive commercial ELISA kit (R\&D Systems) according to the Manufacturer's instructions.

\section{Statistical analysis}

Differences between groups were compared using the Student's $t$-test and Wilcoxon test. All the analyses were performed using Graph-Pad 5 software.

\section{Author contributions}

EF performed experiments, analyzed data, and contributed to write the manuscript; VD, AR, MDG, GB, $\mathrm{CS}, \mathrm{AC}, \mathrm{AO}$ and ADG performed the experiments; FC, GS, PPS, and PR contributed to collect human samples; GM designed the experiments and wrote the manuscript.

\section{ACKNOWLEDGMENTS}

None. 


\section{CONFLICTS OF INTEREST}

None.

\section{FUNDING}

The study was supported by the Associazione Italiana per la Ricerca sul Cancro (IG2016-19223)

\section{REFERENCES}

1. Center MM, Jemal A, Smith RA, Ward E. Worldwide variations in colorectal cancer. CA Cancer J Clin. 2009; 59:366-78. https://doi.org/3322/caac.20038.

2. Shacter E, Weitzman SA. Chronic inflammation and cancer. Oncology (Williston Park). 2002; 16:217-26. 29; discussion 30-2.

3. Eaden JA, Abrams KR, Mayberry JF. The risk of colorectal cancer in ulcerative colitis: a meta-analysis. Gut. 2001; 48:526-35.

4. Nowarski R, Gagliani N, Huber S, Flavell RA. Innate immune cells in inflammation and cancer. Cancer Immunol Res. 2013; 1:77-84. https://doi.org/1158/2326-6066.CIR13-0081.

5. Herrera M, Herrera A, Dominguez G, Silva J, Garcia V, Garcia JM, Gomez I, Soldevilla B, Munoz C, Provencio M, Campos-Martin Y, Garcia de Herreros A, Casal I, et al. Cancer-associated fibroblast and M2 macrophage markers together predict outcome in colorectal cancer patients. Cancer Sci. 2013; 104:437-44. https://doi.org/1111/ cas. 12096

6. Baud'huin M, Renault R, Charrier C, Riet A, Moreau A, Brion R, Gouin F, Duplomb L, Heymann D. Interleukin-34 is expressed by giant cell tumours of bone and plays a key role in RANKL-induced osteoclastogenesis. J Pathol. 2010; 221:77-86. https://doi.org/1002/path.2684.

7. Greter M, Lelios I, Pelczar P, Hoeffel G, Price J, Leboeuf M, Kundig TM, Frei K, Ginhoux F, Merad M, Becher B. Stroma-derived interleukin-34 controls the development and maintenance of langerhans cells and the maintenance of microglia. Immunity. 2012; 37:1050-60. https://doi. org/1016/j.immuni.2012.11.001.

8. Wang Y, Szretter KJ, Vermi W, Gilfillan S, Rossini C, Cella M, Barrow AD, Diamond MS, Colonna M. IL-34 is a tissuerestricted ligand of CSF1R required for the development of Langerhans cells and microglia. Nat Immunol. 2012; 13:753-60. https://doi.org/1038/ni.2360.

9. Preisser L, Miot C, Le Guillou-Guillemette H, Beaumont E, Foucher ED, Garo E, Blanchard S, Fremaux I, Croue A, Fouchard I, Lunel-Fabiani F, Boursier J, Roingeard $\mathrm{P}$, et al. IL-34 and macrophage colony-stimulating factor are overexpressed in hepatitis $\mathrm{C}$ virus fibrosis and induce profibrotic macrophages that promote collagen synthesis by hepatic stellate cells. Hepatology. 2014; 60:1879-90. https://doi.org/1002/hep.27328.
10. Chihara T, Suzu S, Hassan R, Chutiwitoonchai N, Hiyoshi M, Motoyoshi K, Kimura F, Okada S. IL-34 and M-CSF share the receptor Fms but are not identical in biological activity and signal activation. Cell Death Differ. 2010; 17:1917-27. https://doi.org/1038/cdd.2010.60.

11. Wei S, Nandi S, Chitu V, Yeung YG, Yu W, Huang M, Williams LT, Lin H, Stanley ER. Functional overlap but differential expression of CSF-1 and IL-34 in their CSF-1 receptor-mediated regulation of myeloid cells. J Leukoc Biol. 2010; 88:495-505. https://doi.org/1189/jlb.1209822.

12. Lin $\mathrm{H}$, Lee E, Hestir $\mathrm{K}$, Leo $\mathrm{C}$, Huang $\mathrm{M}$, Bosch $\mathrm{E}$, Halenbeck R, Wu G, Zhou A, Behrens D, Hollenbaugh D, Linnemann T, Qin M, et al. Discovery of a cytokine and its receptor by functional screening of the extracellular proteome. Science. 2008; 320:807-11. https://doi.org/1126/ science. 1154370 .

13. Byrne PV, Guilbert LJ, Stanley ER. Distribution of cells bearing receptors for a colony-stimulating factor (CSF-1) in murine tissues. J Cell Biol. 1981; 91:848-53.

14. Ma X, Lin WY, Chen Y, Stawicki S, Mukhyala K, Wu Y, Martin F, Bazan JF, Starovasnik MA. Structural basis for the dual recognition of helical cytokines IL-34 and CSF-1 by CSF-1R. Structure. 2012; 20:676-87. https://doi. org/1016/j.str.2012.02.010.

15. Eda H, Shimada H, Beidler DR, Monahan JB. Proinflammatory cytokines, IL-1beta and TNF-alpha, induce expression of interleukin-34 mRNA via JNK- and p44/42 MAPK-NF-kappaB pathway but not p38 pathway in osteoblasts. Rheumatol Int. 2011; 31:1525-30. https://doi. org/1007/s00296-010-1688-7.

16. Eda H, Zhang J, Keith RH, Michener M, Beidler DR, Monahan JB. Macrophage-colony stimulating factor and interleukin-34 induce chemokines in human whole blood. Cytokine. 2010; 52:215-20. https://doi.org/1016/j. cyto.2010.08.005.

17. Franze E, Marafini I, De Simone V, Monteleone I, Caprioli F, Colantoni A, Ortenzi A, Crescenzi F, Izzo R, Sica G, Sileri P, Rossi P, Pallone F, et al. Interleukin-34 Induces Cc-chemokine Ligand 20 in Gut Epithelial Cells. J Crohns Colitis. 2016; 10:87-94. https://doi.org/1093/ecco-jcc/ jjv181.

18. Franze E, Monteleone I, Cupi ML, Mancia P, Caprioli F, Marafini I, Colantoni A, Ortenzi A, Laudisi F, Sica G, Sileri P, Pallone F, Monteleone G. Interleukin-34 sustains inflammatory pathways in the gut. Clin Sci (Lond). 2015; 129:271-80. https://doi.org/1042/CS20150132.

19. Nandi S, Cioce M, Yeung YG, Nieves E, Tesfa L, Lin H, Hsu AW, Halenbeck R, Cheng HY, Gokhan S, Mehler MF, Stanley ER. Receptor-type protein-tyrosine phosphatase zeta is a functional receptor for interleukin-34. J Biol Chem. 2013; 288:21972-86. https://doi.org/1074/jbc. M112.442731.

20. Segaliny AI, Mohamadi A, Dizier B, Lokajczyk A, Brion R, Lanel R, Amiaud J, Charrier C, Boisson-Vidal C, Heymann D. Interleukin-34 promotes tumor progression 
and metastatic process in osteosarcoma through induction of angiogenesis and macrophage recruitment. Int J Cancer. 2015; 137:73-85. https://doi.org/1002/ijc.29376.

21. Booker BE, Clark RS, Pellom ST, Adunyah SE. Interleukin-34 induces monocytic-like differentiation in leukemia cell lines. Int J Biochem Mol Biol. 2015; 6:1-16.

22. Baghdadi M, Wada H, Nakanishi S, Abe H, Han N, Putra WE, Endo D, Watari H, Sakuragi N, Hida Y, Kaga K, Miyagi Y, Yokose T, et al. Chemotherapy-Induced IL34 Enhances Immunosuppression by Tumor-Associated Macrophages and Mediates Survival of Chemoresistant Lung Cancer Cells. Cancer Res. 2016; 76:6030-42. https:// doi.org/1158/0008-5472.CAN-16-1170.

23. Raggi C, Correnti M, Sica A, Andersen JB, Cardinale V, Alvaro D, Chiorino G, Forti E, Glaser S, Alpini G, Destro A, Sozio F, Di Tommaso L, et al. Cholangiocarcinoma stem-like subset shapes tumor-initiating niche by educating associated macrophages. J Hepatol. 2017; 66:102-15. https://doi.org/1016/j.jhep.2016.08.012.

24. DeNardo DG, Brennan DJ, Rexhepaj E, Ruffell B, Shiao SL, Madden SF, Gallagher WM, Wadhwani N, Keil SD, Junaid SA, Rugo HS, Hwang ES, Jirstrom K, et al. Leukocyte complexity predicts breast cancer survival and functionally regulates response to chemotherapy. Cancer Discov. 2011; 1:54-67. https://doi.org/1158/2159-8274. CD-10-0028.

25. Foucher ED, Blanchard S, Preisser L, Garo E, Ifrah N, Guardiola P, Delneste Y, Jeannin P. IL-34 induces the differentiation of human monocytes into immunosuppressive macrophages. antagonistic effects of GM-CSF and IFNgamma. PLoS One. 2013; 8:e56045. https://doi.org/1371/journal.pone.0056045.

26. Al Obeed OA, Alkhayal KA, Al Sheikh A, Zubaidi AM, Vaali-Mohammed MA, Boushey R, McKerrow JH, Abdulla $\mathrm{MH}$. Increased expression of tumor necrosis factor-alpha is associated with advanced colorectal cancer stages. World J Gastroenterol. 2014; 20:18390-6. https://doi.org/3748/wjg. v20.i48.18390.

27. Waldner MJ, Foersch S, Neurath MF. Interleukin-6--a key regulator of colorectal cancer development. Int J Biol Sci. 2012; 8:1248-53. https://doi.org/7150/ijbs.4614.

28. Cui G, Yuan A, Goll R, Florholmen J. IL-17A in the tumor microenvironment of the human colorectal adenomacarcinoma sequence. Scand J Gastroenterol. 2012; 47:130412. https://doi.org/3109/00365521.2012.725089.

29. Beatty GL, Paterson Y. IFN-gamma can promote tumor evasion of the immune system in vivo by down-regulating cellular levels of an endogenous tumor antigen. J Immunol. 2000; 165:5502-8.

30. De Simone V, Franze E, Ronchetti G, Colantoni A, Fantini MC, Di Fusco D, Sica GS, Sileri P, MacDonald TT, Pallone F, Monteleone G, Stolfi C. Th17-type cytokines, IL-6 and TNF-alpha synergistically activate STAT3 and NF-kB to promote colorectal cancer cell growth. Oncogene. 2015; 34:3493-503. https://doi.org/1038/onc.2014.286.

31. Wang S, Liu Z, Wang L, Zhang X. NF-kappaB signaling pathway, inflammation and colorectal cancer. Cell Mol Immunol. 2009; 6:327-34. https://doi.org/1038/ cmi.2009.43.

32. Balmanno K, Cook SJ. Tumour cell survival signalling by the ERK1/2 pathway. Cell Death Differ. 2009; 16:368-77. https://doi.org/1038/cdd.2008.148.

33. Grossi V, Peserico A, Tezil T, Simone C. p38alpha MAPK pathway: a key factor in colorectal cancer therapy and chemoresistance. World J Gastroenterol. 2014; 20:9744-58. https://doi.org/3748/wjg.v20.i29.9744.

34. Slattery ML, Lundgreen A, Wolff RK. MAP kinase genes and colon and rectal cancer. Carcinogenesis. 2012; 33:2398-408. https://doi.org/1093/carcin/bgs305.

35. Klampfer L. Cytokines, inflammation and colon cancer. Curr Cancer Drug Targets. 2011; 11:451-64.

36. Koshida Y, Kuranami M, Watanabe M. Interaction between stromal fibroblasts and colorectal cancer cells in the expression of vascular endothelial growth factor. J Surg Res. 2006; 134:270-7. https://doi.org/1016/j.jss.2006.02.025.

37. Abiko K, Matsumura N, Hamanishi J, Horikawa N, Murakami R, Yamaguchi K, Yoshioka Y, Baba T, Konishi I, Mandai M. IFN-gamma from lymphocytes induces PD-L1 expression and promotes progression of ovarian cancer. Br J Cancer. 2015; 112:1501-9. https://doi.org/1038/ bjc.2015.101.

38. Liu H, Leo C, Chen X, Wong BR, Williams LT, Lin H, He X. The mechanism of shared but distinct CSF-1R signaling by the non-homologous cytokines IL-34 and CSF-1. Biochim Biophys Acta. 2012; 1824:938-45. https://doi.org/1016/j. bbapap.2012.04.012.

39. Zhou SL, Hu ZQ, Zhou ZJ, Dai Z, Wang Z, Cao Y, Fan J, Huang XW, Zhou J. miR-28-5p-IL-34-macrophage feedback loop modulates hepatocellular carcinoma metastasis. Hepatology. 2016; 63:1560-75. https://doi. org/1002/hep.28445.

40. Chen T, Wang X, Guo L, Wu M, Duan Z, Lv J, Tai W, Renganathan H, Didier R, Li J, Sun D, Chen X, He X, et al. Embryonic Stem Cells Promoting Macrophage Survival and Function are Crucial for Teratoma Development. Front Immunol. 2014; 5:275. https://doi.org/3389/ fimmu.2014.00275.

41. Valencia X, Stephens G, Goldbach-Mansky R, Wilson M, Shevach EM, Lipsky PE. TNF downmodulates the function of human CD4+CD25hi T-regulatory cells. Blood. 2006; 108:253-61. https://doi.org/1182/blood-2005-11-4567.

42. Pasare C, Medzhitov R. Toll pathway-dependent blockade of CD4+CD25+ T cell-mediated suppression by dendritic cells. Science. 2003; 299:1033-6. https://doi.org/1126/ science. 1078231 . 
43. Belluco C, Nitti D, Frantz M, Toppan P, Basso D, Plebani M, Lise M, Jessup JM. Interleukin-6 blood level is associated with circulating carcinoembryonic antigen and prognosis in patients with colorectal cancer. Ann Surg Oncol. 2000; 7:133-8.
44. Foucher ED, Blanchard S, Preisser L, Descamps P, Ifrah N, Delneste Y, Jeannin P. IL-34- and M-CSF-induced macrophages switch memory $\mathrm{T}$ cells into Th17 cells via membrane IL-1alpha. Eur J Immunol. 2015; 45:1092-102. https://doi.org/1002/eji.201444606. 